\title{
Enantioselective Synthesis of Tungsten Trimetallic Cluster Chalcogenides
}

\author{
Eva $M^{a}$ Guillamón, ${ }^{a}$ Marta Blasco, ${ }^{a}$ Rosa Llusar ${ }^{*}, a$ \\ a Departament de Química Física i Analítica, Universitat Jaume I, Av. Sos Baynat s/n, 12071 \\ Castelló, Spain
}

AUTHOR EMAIL ADDRESS: * author for correspondence: rosa.llusar@uji.es CORRESPONDING AUTHOR

a Dept. de Química Física i Analítica, Universitat Jaume I, Av. Sos Baynat s/n, 12071 Castelló, Spain: E-mail: rosa.llusar@uji.es; Tel: +34 964728086; Fax: +34 964728066; Homepage: http://www.grupo-rllusar.uji.es 


\begin{abstract}
Excision of $\left\{\mathrm{W}_{3} \mathrm{Q}_{7} \mathrm{Br}_{4}\right\}_{\mathrm{n}}(\mathrm{Q}=\mathrm{S}$, Se) of polymeric phases using chiral diphosphines is a general procedure to synthesize optically pure trinuclear clusters. Chiral transfer from the enantiomerically pure diphosphines (+)-1,2-bis[2,5-(dimethylphospholan-1-yl)]ethane, $(R, R)$-Me-BPE, (-)-1,2-bis[2,5(dimethylphospholan-1-yl)]ethane, $\quad(S, S)-\mathrm{Me}-\mathrm{BPE}, \quad$ and $\quad(-)-1,2-\mathrm{bis}[2,5-($ dimethylphospholan-1yl)]benzene, $(R, R)$-DUPHOS, to the inorganic phase affords enantiopure $P$-[ $\left[\mathrm{W}_{3} \mathrm{~S}_{4} \mathrm{Br}_{3}((R, R)-\mathrm{Me}-\right.$ $\left.\mathrm{BPE})_{3}\right]^{+}, \quad M-\left[\mathrm{W}_{3} \mathrm{~S}_{4} \mathrm{Br}_{3}((S, S)-\mathrm{Me}-\mathrm{BPE})_{3}\right]^{+}\left(M-\mathbf{1}^{+}\right), \quad P-\left[\mathrm{W}_{3} \mathrm{Se}_{4} \mathrm{Br}_{3}((R, R)-\mathrm{Me}-\mathrm{BPE})_{3}\right]^{+}\left(P-2^{+}\right)$and $P-$ $\left[\mathrm{W}_{3} \mathrm{~S}_{4} \mathrm{Br}_{3}((R, R)-\mathrm{DUPHOS})_{3}\right]^{+}\left(P-\mathbf{3}^{+}\right)$clusters. The central $\mathrm{W}_{3}\left(\mu_{3}-\mathrm{Q}\right)(\mu-\mathrm{Q})$ unit defines an incomplete cuboidal core with the capping chalcogen lying on a three-fold axis and an effective $\mathrm{C}_{3}$ symmetry. Symbols $P$ - and $M$ - are used to indicate the rotation of the bromine atoms around the $\mathrm{C}_{3}$ axis, with the chalcogen atom pointing towards the viewer. Invariably, $P-\mathrm{W}_{3} \mathrm{Q}_{4}$ complexes are obtained starting from $(R, R)$-diphosphines, while its $M-\mathrm{W}_{3} \mathrm{Q}_{4}$ enantiomer is isolated in the presence of $(S, S)$-diphosphines. All complexes have been structurally characterized by single crystal X-ray diffraction and its enantiomeric character confirmed by CD spectroscopy.
\end{abstract}

\title{
Keywords
}

Chirality $\cdot$ trimetallic clusters $\cdot$ diphosphine ligands $\cdot$ tungsten $\cdot$ chalcogen 


\section{Introduction}

Cuboidal transition-metal clusters constitute a large family of multimetallic compounds present in both industrial and biological catalytic processes. In particular, molybdenum and tungsten heterometallic $\mathrm{M}_{3} \mathrm{M}^{\prime} \mathrm{S}_{4}\left(\mathrm{M}^{\prime}=\right.$ transition metal) sulfides have been proposed as models for metalloenzimes [1] or industrial hidrodesulfurization $\left(\mathrm{M}^{\prime}=\mathrm{Ni}\right.$ or $\left.\mathrm{Co}\right)$ catalysts $[2,3]$. Hidai et al . have recently reviewed the main catalytic functions of cubane-type transition metal $\mathrm{M}_{4} \mathrm{~S}_{4}$ compounds in different areas of chemistry and, as expected, their catalytic activity is closely related to the nature of the heterometal $\mathrm{M}^{\prime}$. Thereby, $\mathrm{Mo}_{3} \mathrm{PdS}_{4}$ [4] and $\mathrm{Mo}_{3} \mathrm{NiS}_{4}$ clusters [5] catalyze the stereoselective addition of alcohols or carboxylic acids to electron-deficient alkynes, while $\mathrm{Mo}_{3} \mathrm{RuS}_{4}$ complexes are efficient catalysts in the cleavage of the N-N hydrazine bond [6]. Our group has also shown that $\mathrm{Mo}_{3} \mathrm{CuS}_{4}$ clusters catalyze the intra- and intermolecular cyclopropanation of diazo compounds although enantioselectivity is only moderate $[7,8]$. In addition, trimetallic molybdenum and tungsten $\mathrm{M}_{3} \mathrm{~S}_{4}(\mathrm{M}=\mathrm{Mo}, \mathrm{W})$ complexes are efficient catalyst in the selective hydrodefluorination of pentafluoropyridine in the para position [9] while $\mathrm{Mo}_{3} \mathrm{~S}_{4}$ compounds catalyze the selective conversion of aromatic nitro derivatives to their corresponding anilines [10]. In spite of all applications found for cubane-type $\mathrm{M}_{3} \mathrm{~S}_{4}$ and $\mathrm{M}_{3} \mathrm{M}^{\prime} \mathrm{S}_{4}$ complexes as catalysts, their role in asymmetric processes is very limited due to the scarce number of optically pure cuboidal complexes [11-13].

Along the years we have prepared and isolated a large number of molybdenum and tungsten diphosphino clusters of formula $\left.\left[\mathrm{M}_{3} \mathrm{Q}_{4} \mathrm{X}_{3} \text { (diphosphine }\right)_{3}\right]^{+}(\mathrm{M}=\mathrm{Mo}, \mathrm{W} ; \mathrm{Q}=\mathrm{S}, \mathrm{Se} ; \mathrm{X}=\mathrm{Cl}, \mathrm{Br}, \mathrm{H}, \mathrm{OH}$; HS; diphosphine=dmpe, dppe, dhmpe, dhprpe, dhbupe, Me-BPE, TTF-dppe) [14-21]. The specific coordination of the bidentate ligand to the incomplete cubane-type $\mathrm{M}_{3} \mathrm{~S}_{4}$ unit, with one phosphorus atom located trans to the capping sulfur and the other trans to the bridging sulfur, results in $C_{3^{-}}$ symmetry trimetallic complexes with backbone chirality, as represented in Scheme 1. In these cluster compounds, the three metal centers are stereogenic so that, $P$ (clockwise) and $M$ 
(anticlockwise) descriptors are used to assign the absolute configuration. Obviously, in the absence of an optically pure source, these complexes are obtained as racemic mixtures. In recent years, chirality has become a pursued and demanded property since most drugs, fertilizers or flavors are obtained from asymmetric catalyzed reactions [22-24]. In this context, the synthesis of optically pure cuboidal complexes continues to be a challenge.
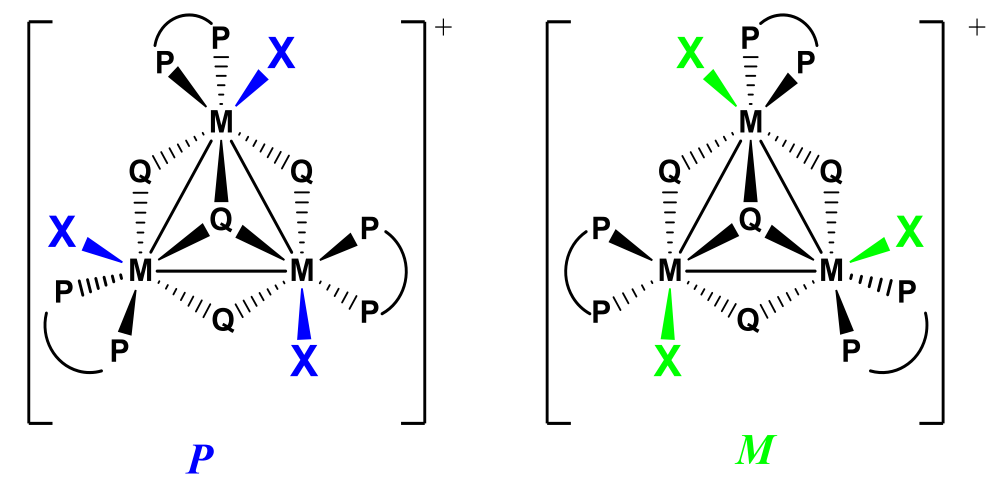

\section{Scheme 1}

Chiral coordination complexes and assemblies can be generated in numerous ways. However, general strategies to afford enantiopure inorganic complexes are still much less developed from those regarding enantiopure organic substrates as stereochemistry at the metal center remains unpredictable [25-27]. In order to afford optically active trinuclear $\mathrm{M}_{3} \mathrm{~S}_{4}$ units, two different approaches can be considered. The first one consists in the resolution of the racemic mixtures via association with a chiral shift counterion, such as TRISPHAT (tris(tetrachlorobenzenediolato)phosphate-(V)), which gives rise to the formation of supramolecular structures [28]. The success of this methodology lies in the configurational stability of the cluster cation at room and high temperatures. All attempts to resolve racemic $\left[\mathrm{Mo}_{3} \mathrm{~S}_{4} \mathrm{Cl}_{3}(\mathrm{dppe})_{3}\right]^{+}$cation mixtures by association with enantiopure $\Delta$ - or $\Lambda$ TRISPHAT anions were unsuccessful [29]. The second strategy is based on the transfer of chiral information into the metal center through the use of organic ligands whose configuration can be easily controlled. Our group has been able to prepare a family of enantiomerically pure $\mathrm{Mo}_{3} \mathrm{Q}_{4}(\mathrm{Q}=\mathrm{S}$, Se) clusters through a controlled stereoisomeric excision of polymeric $\left\{\mathrm{Mo}_{3} \mathrm{Q}_{7} \mathrm{X}_{2} \mathrm{X}_{4 / 2}\right\}_{\mathrm{n}}(\mathrm{X}=\mathrm{Cl}, \mathrm{Br})$ phases in the presence of the (+)-1,2-bis[2,5- 
(dimethylphospholan-1-yl)]ethane $\quad((R, R)-\mathrm{Me}-\mathrm{BPE})) \quad$ or $\quad(-)-1,2-$ bis[2,5-(dimethylphospholan-1yl)]ethane $((S, S)-\mathrm{Me}-\mathrm{BPE})$ chiral diphosphines. This strategy has been also extended to tungsten with the isolation of the $P$ - $\left[\mathrm{W}_{3} \mathrm{~S}_{4} \mathrm{X}_{3}((R, R)-\mathrm{Me}-\mathrm{BPE})_{3}\right]+(\mathrm{X}=\mathrm{Br}, \mathrm{H})$ bromide and hydride cations [18]. Incidentally, these $\mathrm{Mo}_{3} \mathrm{Q}_{4}$ and $\mathrm{W}_{3} \mathrm{Q}_{4}$ trimetallic clusters can act as metalloligands in front of a second transition metal to afford heterometallic $\mathrm{M}_{3} \mathrm{M}^{\prime} \mathrm{Q}_{4}\left(\mathrm{M}^{\prime}=\right.$ transition metal) cubane-type compounds [30].

Motivated by the limited number of examples of enantiomerically pure $\left.\left[\mathrm{W}_{3} \mathrm{Q}_{4} \mathrm{X}_{3} \text { (diphosphine }\right)_{3}\right]^{+}$complexes, we explore in this work the generality of the excision reaction of polymeric $\left\{\mathrm{W}_{3} \mathrm{Q}_{7} \mathrm{Br}_{2} \mathrm{Br}_{4 / 2}\right\}_{n}$ phases with chiral diphosphines, as a rational route to access enantiopure cuboidal $\left[\mathrm{W}_{3} \mathrm{Q}_{4} \mathrm{X}_{3}(\text { diphosphine })_{3}\right]^{+}$clusters. The $(R, R)$-DUPHOS $((-)-1,2-b i s[2,5-$ (dimethylphospholan-1-yl)]benzene) diphosphine has been employed for the first time as excision agent and selenide polymeric phases are also excellent precursors for the isolation of optically pure $\mathrm{W}_{3} \mathrm{Se}_{4}$ complexes. The new complexes have been fully characterized by spectroscopic and spectrometric techniques and their crystal structures determined by single crystal X-ray diffraction experiments.

\section{Experimental section}

\subsection{General methods and materials}

All reactions were carried out under a nitrogen atmosphere using standard Schlenck techniques. The polymeric $\left\{\mathrm{W}_{3} \mathrm{Q}_{7} \mathrm{Br}_{4}\right\}_{\mathrm{n}}$ phases were prepared according to literature methods [31, 32]. The remaining reactants were obtained from commercial sources. Solvents were dried and degassed by standard methods before use. Chromatographic work was performed by using silica gel (60^). ${ }^{31} \mathrm{P}\left\{{ }^{1} \mathrm{H}\right\}$ NMR spectra were recorded on a Varian-Mercury $300 \mathrm{MHz}$ spectrometer using $\mathrm{CD}_{2} \mathrm{Cl}_{2}$ as solvent. The chemical shift is denoted as $\delta(\mathrm{ppm})$, referenced to external $85 \% \mathrm{H}_{3} \mathrm{PO}_{4}$ and to the residual solvent signal. Electrospray ionization mass spectra (ESI-MS) were recorded on a Micromass Quattro LC instrument at $15-20 \mathrm{~V}$ using dichloromethane as solvent. The chemical 
composition of each peak was assigned by comparison of the isotope experimental pattern with that calculated using the MassLynx NT set program [33]. Circular dichroism measurements were recorded on a JASCO J-810 spectropolarimeter and UV/Vis measurements were carried out by using a Cary 60 spectrometer. The sample solutions were prepared in a quartz cuvette of $1 \mathrm{~cm}$ path length and measured at $25^{\circ} \mathrm{C}$. Elemental analysis was performed in a Euro EA $3000 \mathrm{CHN}$ equipment.

\subsection{Synthesis}

\subsubsection{Synthesis of $M-\left[W_{3} S_{4} B r_{3}((S, S)-M e-B P E)_{3}\right] B r+3 C_{7} H_{8},[M-1] B r+3 C_{7} H_{8}$}

To a suspension of the $\left\{\mathrm{W}_{3} \mathrm{~S}_{7} \mathrm{Br}_{4}\right\}_{\mathrm{n}}$ polymeric phase $(152 \mathrm{mg}, 0.139 \mathrm{mmol})$ in dry acetonitrile (20 $\mathrm{mL})$ was added $(S, S)$-Me-BPE $(170 \mu \mathrm{L}, 0.625 \mathrm{mmol})$. The mixture was refluxed for 24 hours and then, the blue suspension was filtered at room temperature. The filtrate was taken to dryness under vacuum and the solid was dissolved in dichloromethane. Addition of $30 \mathrm{~mL}$ of ether caused the complete precipitation of a blue solid (106 $\mathrm{mg}, 37 \%$ ) which was washed with $25 \mathrm{~mL}$ of a toluene/acetone mixture (95:5).

${ }^{31} \mathrm{P}\left\{{ }^{1} \mathrm{H}\right\}$ NMR (121.47 MHz, $\left.\mathrm{CD}_{2} \mathrm{Cl}_{2}\right): \delta=31.65$ (dd, 3P), $35.88 \mathrm{ppm}(\mathrm{dd}, 3 \mathrm{P})$ (AA'A'BB'B', system); UV/Vis $\left(1.15 \cdot 10^{-4} \mathrm{M}, \mathrm{CH}_{2} \mathrm{Cl}_{2}\right): \lambda(\varepsilon)=364$ (9165), 325 (13982), $278 \mathrm{~nm}\left(23134 \mathrm{~mol}^{-}\right.$ $\left.{ }^{1} \cdot \mathrm{dm}^{3} \cdot \mathrm{cm}^{-1}\right)$; ESI-MS $\left(\mathrm{CH}_{2} \mathrm{Cl}_{2}, 20 \mathrm{~V}\right) \mathrm{m} / \mathrm{z}: 1694 \quad[\mathrm{M}]^{+}$; elemental analysis calcd (\%) for $\mathrm{W}_{3} \mathrm{~S}_{4} \mathrm{Br}_{4} \mathrm{P}_{6} \mathrm{C}_{63} \mathrm{H}_{108}$ : C 36.90, H, 5.31; Found: C 36.3, H 5.2; CD (1.15.10-4 $\left.\mathrm{M}, \mathrm{CH}_{2} \mathrm{Cl}_{2}\right) \lambda(\mathrm{mdeg})$ : 524 (30), 404 (62), 325 (-88), 292 (21), 270 (-132), $243 \mathrm{~nm}(-85)$.

\subsubsection{Synthesis of $P-\left[W_{3} S_{4} B r_{3}((R, R)-M e-B P E)_{3}\right]\left(P F_{6}\right),[P-2] P F_{6}$}

The chiral diphosphine $(R, R)$-Me-BPE $(102 \mathrm{mg}, 0.395 \mathrm{mmol})$ was added to a suspension of $\left\{\mathrm{W}_{3} \mathrm{Se}_{7} \mathrm{Br}_{4}\right\}_{\mathrm{n}}(125 \mathrm{mg}, 0.088 \mathrm{mmol})$ in dry acetonitrile and refluxed for 24 hours. In this case, when the filtrate was taken to dryness under vacuum, the solid was dissolved in dichloromethane and a counterion change was carried out by column chromatography. The compound was adsorbed in a silica gel column and was first washed with $200 \mathrm{~mL}$ acetone. Then, it was eluted with a saturated $\mathrm{KPF}_{6}$ solution in acetone, affording a green-turquoise solution. The solution collected was taken to 
dryness under vacuum and the solid was dissolved in dichloromethane. Addition of ether (30 $\mathrm{mL})$ caused the complete precipitation of a green-turquoise solid (160 mg, 94\%).

${ }^{31} \mathrm{P}\left\{{ }^{1} \mathrm{H}\right\}$ NMR (121.47 MHz, $\left.\mathrm{CD}_{2} \mathrm{Cl}_{2}\right): \delta:-143.87$ (sept, 1P, $\left.{ }^{1} \mathrm{~J}_{\mathrm{P}-\mathrm{F}}=704.0 \mathrm{~Hz}\right), 29.37$ (d, 3P,

$\left.{ }^{2} \mathbf{J}_{\text {P-Pgem }}=6.75 \mathrm{~Hz}\right), 38.83\left(\mathrm{~d}, 3 \mathrm{P},{ }^{2} \mathrm{~J}_{\mathrm{P} \text {-Pgem }}=6.12 \mathrm{~Hz}\right)$; UV/Vis $\left(1.05 \cdot 10^{-4} \mathrm{M}, \mathrm{CH}_{2} \mathrm{Cl}_{2}\right): \lambda(\varepsilon)=635$ (1050), 383 (8771.06), 340 (13013), 291 (18960), $237 \mathrm{~nm}\left(32953 \mathrm{~mol}^{-1} \cdot \mathrm{m}^{3} \cdot \mathrm{cm}^{-1}\right)$; ESI-MS $\left(\mathrm{CH}_{2} \mathrm{Cl}_{2}\right.$, $20 \mathrm{~V}) \mathrm{m} / \mathrm{z}: 1882.2[\mathrm{M}]^{+}$; elemental analysis, Calcd (\%) for $\mathrm{W}_{3} \mathrm{Se}_{4} \mathrm{Br}_{3} \mathrm{P}_{7} \mathrm{~F}_{6} \mathrm{C}_{42} \mathrm{H}_{84}:$ C 24.88, H, 4.18; Found: C 24.64, H 4.31. $C D\left(1.05 \cdot 10^{-4} \mathrm{M}, \mathrm{CH}_{2} \mathrm{Cl}_{2}\right) \lambda$ (mdeg): 667 (20), 448 (-52), 380 (59), 339 (114), 308 (-57), $286(173), 259 \mathrm{~nm}(205)$

\subsubsection{Synthesis of $\mathrm{P}-\left[\mathrm{W}_{3} \mathrm{~S}_{4} \mathrm{Br} r_{3}((\mathrm{R}, \mathrm{R})-\mathrm{Me}-\mathrm{DUPHOS})_{3}\right] \mathrm{Br}+\mathrm{C}_{7} \mathrm{H}_{8},[\mathrm{P}-3] \mathrm{Br}+\mathrm{C}_{7} \mathrm{H}_{8}$}

The $\left\{\mathrm{W}_{3} \mathrm{~S}_{7} \mathrm{Br}_{4}\right\}_{\mathrm{n}}$ polymeric phase $(200 \mathrm{mg}, 0.183 \mathrm{mmol})$ was suspended in dry acetonitrile $(25 \mathrm{~mL})$ and was added $(R, R)-$ Me-DUPHOS $(251 \mathrm{mg}, 0.822 \mathrm{mmol})$. The mixture was refluxed for 48 hours and then, the purple suspension was filtered. The filtrate was taken to dryness under vacuum and the solid was dissolved in dichloromethane. Addition of ether $(40 \mathrm{~mL})$ leaded to the complete precipitation of a purple solid $(240 \mathrm{mg}, 65 \%)$ which was washed with a toluene/acetone mixture (97:3) and benzene $(5 \mathrm{~mL})$.

${ }^{31} \mathrm{P}\left\{{ }^{1} \mathrm{H}\right\}$ NMR (121.47 MHz, $\left.\mathrm{CD}_{2} \mathrm{Cl}_{2}\right): \delta=34.88$ (d, 3P), 42.94 ppm (d, 3P) (AA'A' 'BB'B'” system); UV/Vis $\left(1.25 \cdot 10^{-4} \mathrm{M}, \mathrm{CH}_{2} \mathrm{Cl}_{2}\right): \lambda(\varepsilon)=329(10375), 278 \mathrm{~nm}\left(16535 \mathrm{~mol}^{-1} \cdot \mathrm{dm}^{3} \cdot \mathrm{cm}^{-1}\right) ;$ ESI-MS $\left(\mathrm{CH}_{2} \mathrm{Cl}_{2}, 20 \mathrm{~V}\right) \mathrm{m} / \mathrm{z}: 1838.8[\mathrm{M}]^{+}$; elemental analysis calcd $(\%)$ for $\mathrm{W}_{3} \mathrm{~S}_{4} \mathrm{Br}_{4} \mathrm{P}_{6} \mathrm{C}_{61} \mathrm{H}_{92}: \mathrm{C} 36.44, \mathrm{H}$ 4.61; found: C 36.50, H 5.20; $C D\left(1.20 \cdot 10^{-4} \mathrm{M}, \mathrm{CH}_{2} \mathrm{Cl}_{2}\right) \lambda$ (mdeg): 530 (-36), 432 (-22), 404 (-50), 365 (119), 328 (132), 295 (17), $262 \mathrm{~nm}(201)$

\subsection{X-ray data collection and structure refinement}

Suitable crystals for X-ray studies of $[M-1] \mathrm{Br}$ were grown by slow vapor diffusion of toluene into a sample solution of $[M-1] \mathrm{Br}$ in $\mathrm{CH}_{2} \mathrm{Cl}_{2}$ or diethyl ether into sample solutions of $[P-2] \mathrm{PF}_{6}$ and $[P-3] \mathrm{Br}$ in $\mathrm{CH}_{2} \mathrm{Cl}_{2}$. Crystal evaluation and diffraction data for compounds $[M-1] \mathrm{Br}$ and $[P-3] \mathrm{Br}$ were perfomed on an Agilent Supernova diffractometer equipped with an Atlas CCD detector using MoK $\alpha$ radiation $(\lambda=0.71073 \AA)$. No instrument or crystal instabilities were observed during data 
collection [34]. Absorption corrections based on the Gaussian method [35] for $M-\mathbf{1}^{+}$cluster and Multi-scan method [36] for $P-3^{+}$cluster were applied. Diffraction data for $[P-2] \mathrm{PF}_{6}$ was collected with a Bruker SMART CCD diffractometer using Mo-K $\alpha$ radiation $(\lambda=0.71073 \AA)$ at $\mathrm{T}=296.15(2)$ $\mathrm{K}$. The data were collected with a frame width of $0.3^{\circ}$ in $\Omega$ and a counting time of $25 \mathrm{~s}$ per frame at a crystal-detector distance of $4 \mathrm{~cm}$. Data reduction was carried out using the programme SAINT [37] and SADABS software [38] was used for absorption correction. Structure of [M-1]Br was solved by charge-flipping methods using Superflip [39] while structures of $[P-2] \mathrm{PF}_{6}$ and $[P-3] \mathrm{Br}$ were solved by direct methods using SHELXS-97 [40] and refined by the full-matrix method based on $\mathrm{F}^{2}$ with the program SHELXL-97 using the OLEX software package [41]. The graphics were performed with the Diamond visual crystal structure information system software [42]. For compound $[M-1] \mathrm{Br}$, all atoms in the cluster cation as well as the $\mathrm{Br}$ anion were refined anisotropically. This salt cystallises with two $\mathrm{CH}_{2} \mathrm{Cl}_{2}$ and one toluene solvent molecules. One of the carbon atoms (C43) of adichloromethane molecule had to be refined isotropically. The carbon atoms of the toluene molecule were also refined isotropically and their bond distances were constrained to a fixed value of $1.36 \AA$. For compounds $[P-2] \mathrm{PF}_{6}$ and $[P-3] \mathrm{Br} \cdot 2 \mathrm{CH}_{2} \mathrm{Cl}_{2}$ all atoms were refined anisotropically. The $\mathrm{H}$ atoms in all three clusters were positioned geometrically, assigned isotropic thermal parameters and allowed to ride on their respective parent carbon atoms. Three top peaks of ca. 5.32, 4.18 and $3.1 \mathrm{e} \cdot \AA^{-3}$ remained in the last Fourier map of the $M$ - $\left[\mathrm{W}_{3} \mathrm{~S}_{4} \mathrm{Br}_{3}((\mathrm{~S}, \mathrm{~S})-\mathrm{Me}-\mathrm{BPE})_{3}\right] \mathrm{Br}$ structure although these residual density were too close to the heavy atom (ca. $0.86,0.81$ and $0.9 \AA$, respectively) to be included in the model. Flack parameter was refined and used to assess the absolute structure [43-45]. Crystal data and structure refinement information for all compounds are summarized in Table 1. 
Table 1. Crystallographic data for $M$ - $\left[\mathrm{W}_{3} \mathrm{~S}_{4} \mathrm{Br}_{3}((S, S)-\mathrm{Me}-\mathrm{BPE})_{3}\right] \mathrm{Br} \cdot 2 \mathrm{CH}_{2} \mathrm{Cl}_{2} \cdot \mathrm{C}_{7} \mathrm{H}_{8}, \quad[M-$ 1] $\mathrm{Br} \cdot 2 \mathrm{CH}_{2} \mathrm{Cl}_{2} \cdot \mathrm{C}_{7} \mathrm{H}_{8}, \quad P-\left[\mathrm{W}_{3} \mathrm{Se}_{4} \mathrm{Br}_{3}((R, R)-\mathrm{Me}-\mathrm{BPE})_{3}\right] \mathrm{PF}_{6}, \quad[P-2] \mathrm{PF}_{6}, \quad P-\left[\mathrm{W}_{3} \mathrm{~S}_{4} \mathrm{Br}_{3}((R, R)-\right.$ DUPHOS $\left.)_{3}\right] \mathrm{Br} \cdot 2 \mathrm{CH}_{2} \mathrm{Cl}_{2},[P-3] \mathrm{Br} \cdot 2 \mathrm{CH}_{2} \mathrm{Cl}_{2}$.

\begin{tabular}{|c|c|c|c|}
\hline & {$[M-1] \mathrm{Br} \cdot 2 \mathrm{CH}_{2} \mathrm{Cl}_{2} \cdot \mathrm{C}_{7} \mathrm{H}_{8}$} & {$[P-2] \mathrm{PF}_{6}$} & {$[P-3] \mathrm{Br} \cdot 2 \mathrm{CH}_{2} \mathrm{Cl}_{2}$} \\
\hline Empirical formula & $\mathrm{C}_{51} \mathrm{H}_{96} \mathrm{Br}_{4} \mathrm{Cl}_{4} \mathrm{P}_{6} \mathrm{~S}_{4} \mathrm{~W}_{3}$ & $\mathrm{C}_{42} \mathrm{H}_{84} \mathrm{Br}_{3} \mathrm{P}_{7} \mathrm{Se}_{4} \mathrm{~W}_{3} \mathrm{~F}_{6}$ & $\mathrm{C}_{56} \mathrm{H}_{88} \mathrm{Br}_{4} \mathrm{Cl}_{4} \mathrm{P}_{6} \mathrm{~S}_{4} \mathrm{~W}_{3}$ \\
\hline Formula weight & 2036.32 & 2027 & 2088.31 \\
\hline Temperature (K) & 293(2) & 296.15 & $200(2)$ \\
\hline Space group & $P 2_{1}$ & $R 3$ & $P 2_{1}$ \\
\hline \multicolumn{4}{|l|}{ Unit cell dimensions } \\
\hline$a, \AA$ & $11.9974(16)$ & $15.6097(11)$ & $12.02802(15)$ \\
\hline$\beta \equiv$ & $98.107(12)$ & 90 & $93.6703(14)$ \\
\hline$\gamma \equiv$ & 90 & 120 & 90 \\
\hline Volume, $\AA^{3}$ & $3473.21(8)$ & $4900.9(10)$ & $3557.28(9)$ \\
\hline $\mathrm{Z}$ & 2 & 3 & 2 \\
\hline $\mathrm{D}_{\text {calc }}\left(\mathrm{Mg} \mathrm{m}^{-3}\right)$ & 1.947 & 2.060 & 1.950 \\
\hline Absorption coeffient $\left(\mathrm{mm}^{-1}\right)$ & 7.702 & 9.547 & 7.523 \\
\hline \multirow{2}{*}{ Index ranges } & $-26 \leq \mathrm{k} \leq 26$ & $-18 \leq \mathrm{k} \leq 18$ & $-32 \leq \mathrm{k} \leq 30$ \\
\hline & $-20 \leq 1 \leq 19$ & $-16 \leq 1 \leq 27$ & $-16 \leq 1 \leq 16$ \\
\hline Reflections collected & 76264 & 9032 & 40359 \\
\hline Independent reflections & $17297\left[\mathrm{R}_{\mathrm{int}}=0.0368\right]$ & $3092\left[\mathrm{R}_{\mathrm{int}}=0.0384\right]$ & $16591\left[\mathrm{R}_{\mathrm{int}}=0.0595\right]$ \\
\hline Absorption correction & gaussian & Multi-scan & Multi-scan \\
\hline Refinement method & full-matrix least-squares on $\mathrm{F}^{2}$ & full-matrix least-squares on $\mathrm{F}^{2}$ & full-matrix least-squares on $\mathrm{F}^{2}$ \\
\hline Data/restraints/parameters & $17297 / 8 / 622$ & $3092 / 1 / 196$ & $16591 / 1 / 706$ \\
\hline Goodness-of-fit on $F^{2}$ & 1.043 & 1.123 & 1.051 \\
\hline Final $\mathrm{R}$ indices $[\mathrm{I}>2 \sigma(\mathrm{I})]$ & $\mathrm{R}_{1}=0.0333, \mathrm{wR}_{2}=0.0819$ & $\mathrm{R}_{1}=0.0322, \mathrm{wR}_{2}=0.0838$ & $\mathrm{R}_{1}=0.0509, \mathrm{wR}_{2}=0.1126$ \\
\hline $\mathrm{R}$ indices (all data) & $\mathrm{R}_{1}=0.0358, \mathrm{wR}_{2}=0.0840$ & $\mathrm{R}_{1}=0.0365, \mathrm{wR}_{2}=0.0861$ & $\mathrm{R}_{1}=0.0670, \mathrm{wR}_{2}=0.1271$ \\
\hline Largest difference in peak and hole $\left(\mathrm{e} \cdot \mathrm{A}^{-3}\right)$ & 5.32 and -1.77 & 1.50 and -1.35 & 2.10 and -2.10 \\
\hline Flack parameter & $-0.016(3)$ & $0.032(13)$ & $-0.015(7)$ \\
\hline
\end{tabular}




\section{Results and discussion}

\subsection{Synthesis and characterization}

Nowadays, excision reaction of $\left\{\mathrm{M}_{3} \mathrm{Q}_{7} \mathrm{X}_{4 / 2} \mathrm{X}_{2}\right\}_{\mathrm{n}}$ polymeric phases is considered as a rational and well-established procedure to prepare cuboidal cubane-type clusters with backbone chirality. This synthetic methodology requires the presence of species with high affinity for chalcogen atoms, i.e. phosphines, to make feasible the dimensional reduction. As already mentioned in the introduction, racemic mixtures are invariably obtained when non-chiral diphosphines are employed as dimensional reducing agents. Interestingly, the reaction showed a unique efficiency and stereoselectivity when $\left\{\mathrm{Mo}_{3} \mathrm{~S}_{7} \mathrm{Cl}_{4 / 2} \mathrm{Cl}_{2}\right\}_{\mathrm{n}}$ phases are reacted with chiral diphosphines, namely $(R, R)$ Me-BPE or $(S, S)-\mathrm{Me}-\mathrm{BPE}$, to afford the trinuclear $P$-[ $\left[\mathrm{Mo}_{3} \mathrm{~S}_{4} \mathrm{Cl}_{3}((R, R)-\mathrm{Me}-\mathrm{BPE})_{3}\right]^{+}$and $M$ $\left[\mathrm{Mo}_{3} \mathrm{~S}_{4} \mathrm{Cl}_{3}((R, R)-\mathrm{Me}-\mathrm{BPE})_{3}\right]^{+}$stereoisomers [7], respectively, as represented in Scheme 2. This synthetic procedure has been extended to the bromine and selenium analogues and, more recently, the trimetallic $P$ - $\left[\mathrm{W}_{3} \mathrm{~S}_{4} \mathrm{Br}_{3}((R, R)-\mathrm{Me}-\mathrm{BPE})_{3}\right]^{+}$complex was also isolated. [18]

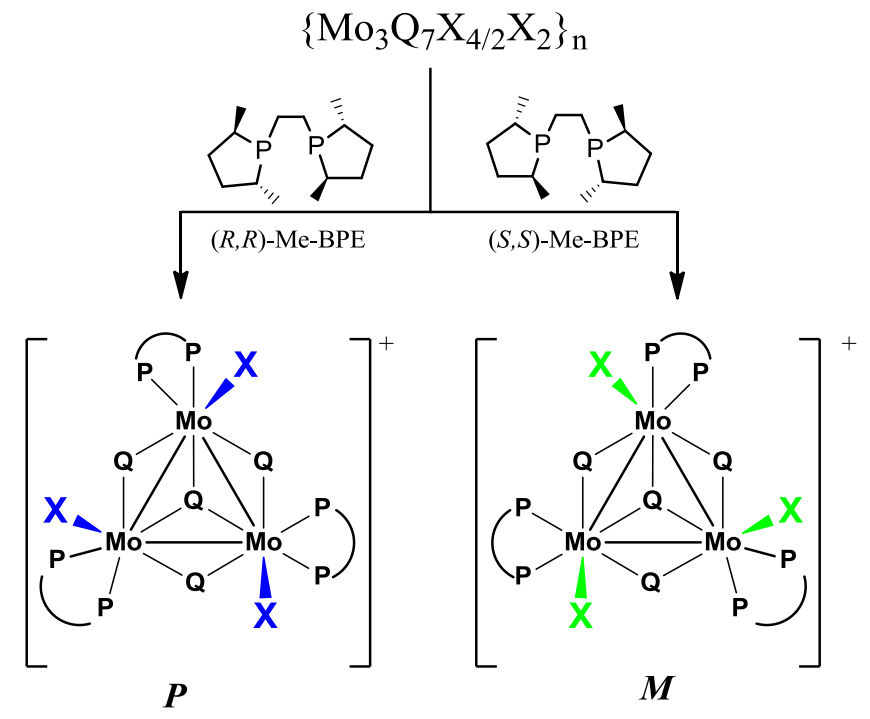

\section{Scheme 2}

To validate the generality of this synthetic strategy, we have reacted the $(S, S)$-Me-BPE diphosphine with $\left\{\mathrm{W}_{3} \mathrm{~S}_{7} \mathrm{Br}_{4 / 2} \mathrm{Br}_{2}\right\}_{\mathrm{n}}$ and the $M$-[ $\left[\mathrm{W}_{3} \mathrm{~S}_{4} \mathrm{Br}_{3}((R, R)-\mathrm{Me}-\mathrm{BPE})_{3}\right]^{+}\left(M-\mathbf{1}^{+}\right)$diastereoisomer has been characterized as the only reaction product. The absolute configuration of $M-\mathbf{1}^{+}$as $M$ has been determined by X-ray crystallography, as detailed in the following section. The enantiomeric character of $M-\mathbf{1}^{+}$with regard to the $P-\left[\mathrm{W}_{3} \mathrm{~S}_{4} \mathrm{Br}_{3}((S, S)-\mathrm{Me}-\mathrm{BPE})_{3}\right]^{+}$cation has been proved by CD 
measurements, shown in Figure 1. Compound $M-\mathbf{1}^{+}$displays three signals at $\lambda_{\max }=270,325$ and $404 \mathrm{~nm}$ associated to $-132,-88$ and +62 mdeg with similar intensities, but opposite signs to those produced by the $P$ - $\left[\mathrm{W}_{3} \mathrm{~S}_{4} \mathrm{Br}_{3}((R, R)-\mathrm{Me}-\mathrm{BPE})_{3}\right]^{+}$complex giving support to the enantiomerism of the two complexes [18]. As expected, both compounds have the same ESI-MS and $\mathrm{P}\left\{{ }^{1} \mathrm{H}\right\}$-NMR spectra. The last one shows two double of doublets at $\delta=31.65 \mathrm{ppm}$ (three $\mathrm{P}$ atoms) and at $\delta=35.88 \mathrm{ppm}$ (three $\mathrm{P}$ atoms) and the typical satellites due to the coupling with the ${ }^{183} \mathrm{~W}$ nuclei.

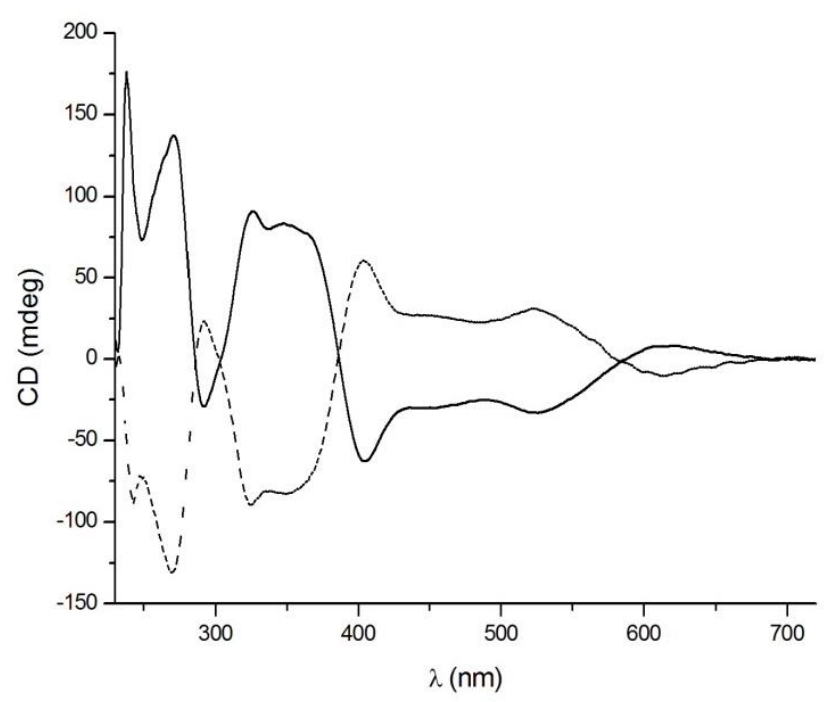

Figure 1. $\mathrm{CD}$ spectra of $P-\left[\mathrm{W}_{3} \mathrm{~S}_{4} \mathrm{Br}_{3}(\mathrm{Me}-\mathrm{BPE})_{3}\right]^{+}(-)$and $M-\mathbf{1}^{+}$( --- ) enantiomers in dichloromethane at $25^{\circ} \mathrm{C}$ at $1.13 \cdot 10^{-4} \mathrm{M}$ and $1.15 \cdot 10^{-4} \mathrm{M}$, respectively.

As previously observed for the molybdenum system, reaction of the selenium $\left\{\mathrm{W}_{3} \mathrm{Se}_{7} \mathrm{Br}_{4}\right\}_{\mathrm{n}}$ phase with $(R, R)$-Me-BPE in boiling acetonitrile affords the optically pure $P$-[ $\left[\mathrm{W}_{3} \mathrm{Se}_{4} \mathrm{Br}_{3}((R, R)-\mathrm{Me}\right.$ $\left.\mathrm{BPE})_{3}\right]^{+}\left(P-\mathbf{2}^{+}\right)$cation in quantitative yields while their sulfur analogues were only obtained in moderate yields, $c a .50 \%$. Again, X-ray crystallography (see vide infra) and CD spectroscopy give support to the absolute configuration of this complex as $P$. At this point, we decided to investigate whether the stereoselectivity of the excision of polymeric $\left\{\mathrm{W}_{3} \mathrm{Q}_{7} \mathrm{X}_{4 / 2} \mathrm{X}_{2}\right\}_{\mathrm{n}}$ phases could be extended to other diphosphines. With this idea in mind, we carried out the excision reaction between $\left\{\mathrm{W}_{3} \mathrm{~S}_{7} \mathrm{Br}_{4}\right\}_{\mathrm{n}}$ in the presence of an excess of $(R, R)$-DUPHOS according to equation (1).

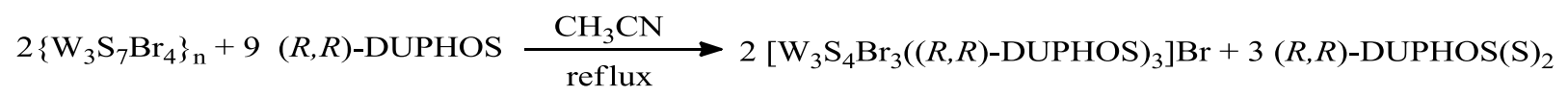


After purification of the reaction mixture, ${ }^{31} \mathrm{P}\left\{{ }^{1} \mathrm{H}\right\}-\mathrm{NMR}$ spectroscopy and ESI-MS spectrometry indicate the presence of a unique diastereoisomer, unequivocally identified as $P$ $\left[\mathrm{W}_{3} \mathrm{~S}_{4} \mathrm{Br}_{3}((R, R)-\mathrm{Me}-\mathrm{DUPHOS})_{3}\right]^{+}\left(P-\mathbf{3}^{+}\right)$, as detailed as follows. CD spectrum of $P-\mathbf{3}^{+}$showed Cotton effects at $\lambda_{\max }=404$ (-50), 365 (119), 328 (132), $262 \mathrm{~nm}$ (201 mdeg) with the same tendency in signs as $P-2^{+}$and the reported $P-\left[\mathrm{W}_{3} \mathrm{~S}_{4} \mathrm{Br}_{3}((R, R)-\mathrm{Me}-\mathrm{BPE})_{3}\right]^{+}$complex, giving support to its absolute configuration as $P$. Nevertheless, $\mathrm{X}$-ray diffraction measurements were carried out in order to ascertain the stereochemistry observed by $\mathrm{CD}$ solution techniques and refinement of Flack parameter determined unequivocally the stereochemistry of the cluster in $[P-3] \mathrm{Br}$ compound. Finally, CD spectra analysis of $M-\mathbf{1}^{+}, P-2^{+}$and $P-3^{+}$compounds revealed only small and subtle differences, being the most remarkable a slight displacement to the red region on going from sulfur to selenium. Therefore, the maximum peaks in the $\mathrm{CD}$ spectra for the whole tungsten family clusters issued in this report are displaced to the blue region when compared to the molybdenum analogues.

\section{2. $\quad$ Crystal structure description}

The crystal structures of the bromide salts of $M-\mathbf{1}^{+}$and $P-\mathbf{3}^{+}$and the hexafluorophosphate salt of $P-2^{+}$ were determined by single-crystal X-ray diffraction. As expected, all three compounds cystallised in non-centrosymmetric space groups, namely, monoclinic $P 2_{1}$ for $[M-1] \mathrm{Br}$ and $[P-3] \mathrm{Br}$, and trigonal $R 3$ for $[P-2] \mathrm{PF}_{6}$. An ORTEP view of the $P-\mathbf{2}^{+}$and $P-\mathbf{3}^{+}$cations is shown in Figure 2. Selected bond distances for $[M-1] \mathrm{Br},[P-2] \mathrm{PF}_{6}$ and $[P-3] \mathrm{Br}$ are listed in Table 2 together with those reported for the $P$ - $\left[\mathrm{W}_{3} \mathrm{~S}_{4} \mathrm{Br}_{3}((\mathrm{R}, \mathrm{R})-\mathrm{Me}-\mathrm{BPE})_{3}\right]^{+}$cation for comparative purposes. The three clusters possess an incomplete cuboidal $\mathrm{W}_{3} \mathrm{Q}_{4}$ core in which the tungsten atoms define an equilateral triangle with two phosphorus atoms of the diphosphine ligand and one bromine atom occupying the outer positions. In all cases, the uniform stereochemistry of the diphosphine ligands as $(R, R)$ or $(S, S)$ was observed with no ambiguity. Flack parameters around zero for all three absolute structures has allowed us to unequivocally assess the stereochemistry of $M-\mathbf{1}^{+}$as $M$ and $P-\mathbf{2}^{+}$and $P-\mathbf{3}^{+}$as $P$. 

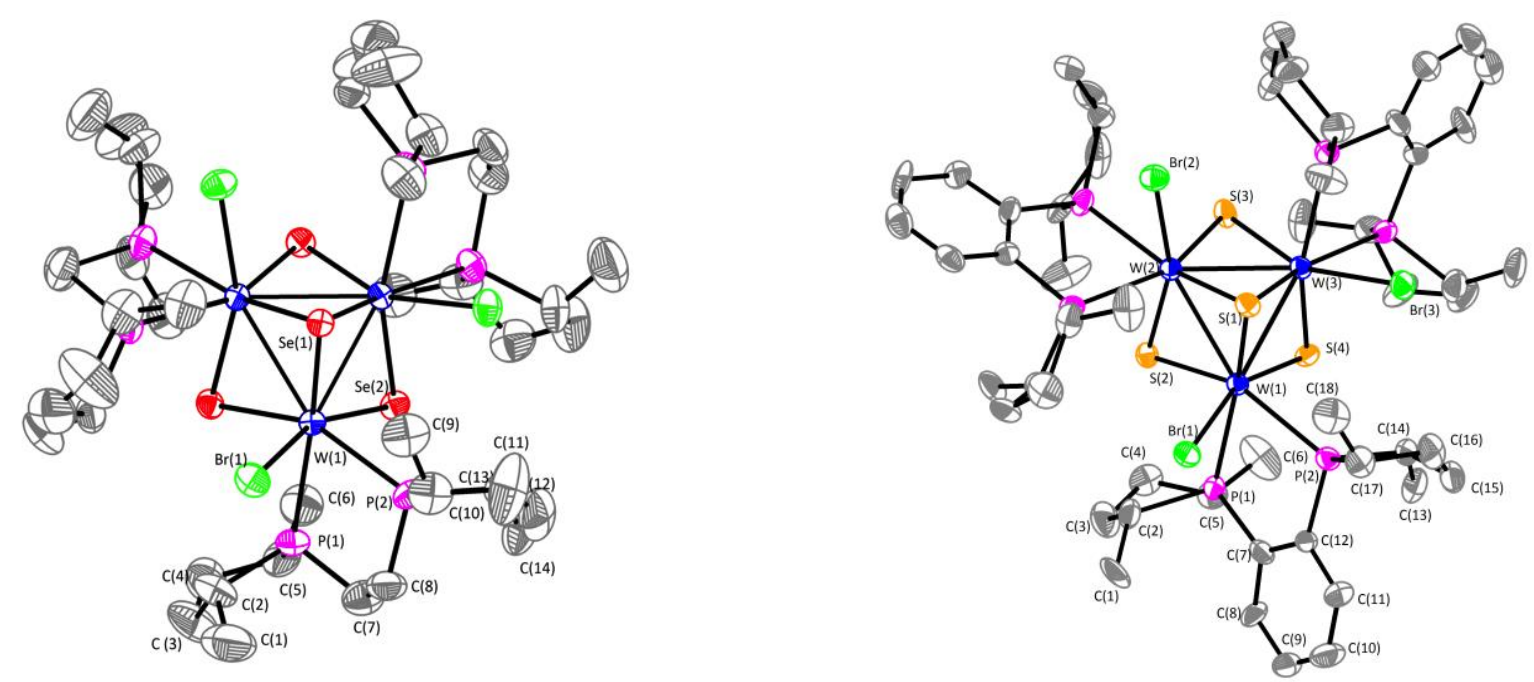

Figure 2. ORTEP representation $(50 \%$ probability ellipsoids) of the cationic clusters $P$ $\left[\mathrm{W}_{3} \mathrm{Se}_{4} \mathrm{Br}_{3}((R, R)-\mathrm{Me}-\mathrm{BPE})_{3}\right]^{+}, P-\mathbf{2}^{+}$and $P-\left[\mathrm{W}_{3} \mathrm{~S}_{4} \mathrm{Br}_{3}((R, R)-\mathrm{DUPHOS})_{3}\right]^{+}, P-\mathbf{3}^{+}$, respectively, with the atom-numbering scheme. Hydrogen atoms have been omitted for clarity.

Table 2. Selected bond distances $(\AA)$ for $[M-1] \mathrm{Br},[P-2] \mathrm{Br}$ and $[P-3] \mathrm{PF}_{6}$.

\begin{tabular}{lcccc}
\hline & {$\left[\mathrm{W}_{3} \mathrm{~S}_{4} \mathrm{Br}_{3}((R, R)-\mathrm{Me}-\mathrm{BPE})_{3}\right]\left(\mathrm{PF}_{6}\right)^{[18]}$} & {$[M-1] \mathrm{Br}^{\mathrm{a}}$} & {$[P-2] \mathrm{PF}_{6}$} & {$[P-3] \mathrm{Br}^{\mathrm{a}}$} \\
\hline $\mathrm{W}-\mathrm{W}$ & $2.793[4]$ & $2.7897[5]$ & $2.8670(8)$ & $2.8102[8]$ \\
$\mathrm{W}-\mu_{3}-\mathrm{Q}(1)$ & $2.371[4]$ & $2.3637[2]$ & $2.4849(18)$ & $2.3737[4]$ \\
$\mathrm{W}-\mu-\mathrm{Q}(2)^{\mathrm{b}}$ & $2.289[5]$ & $2.2893[2]$ & $2.4111(13)$ & $2.293[4]$ \\
$\mathrm{W}-\mu-\mathrm{Q}(2)^{\mathrm{c}}$ & $2.311[6]$ & $2.3163[2]$ & $2.4498(13)$ & $2.3133[4]$ \\
$\mathrm{W}-\mathrm{P}(1)^{\mathrm{d}}$ & $2.559[3]$ & $2.552[2]$ & $2.564(4)$ & $2.553[4]$ \\
$\mathrm{W}-\mathrm{P}(2)^{\mathrm{e}}$ & $2.633[7]$ & $2.6243[2]$ & $2.653(4)$ & $2.6217[4]$ \\
$\mathrm{W}-\mathrm{Br}$ & $2.6303[2]$ & $2.6296[10]$ & $2.6313(15)$ & $2.6247[17]$ \\
\hline
\end{tabular}

${ }^{\mathrm{a}}$ Standard deviations for averaged values are given in square brackets. ${ }^{\mathrm{b}} \mathrm{W}-\mu$-Q distance trans to $\mathrm{W}$ Br bond. ${ }^{\mathrm{c}} \mathrm{W}-\mu-\mathrm{Q}$ distance cis to $\mathrm{W}-\mathrm{Br}$ bond. ${ }^{\mathrm{d}}$ Distance trans to the $\mathrm{W}-\left(\mu_{3}-\mathrm{Q}\right)$ bond. ${ }^{\mathrm{e}}$ Distance cis to the $\mathrm{W}$ $\left(\mu_{3}-\mathrm{Q}\right)$ bond.

Metal-metal bond distances in $M$ - $\left[\mathrm{W}_{3} \mathrm{~S}_{4} \mathrm{Br}_{3}((S, S)-\mathrm{Me}-\mathrm{BPE})_{3}\right]^{+}$and $P$ - $\left[\mathrm{W}_{3} \mathrm{~S}_{4} \mathrm{Br}_{3}((R, R)-\right.$ DUPHOS $\left.)_{3}\right]^{+}$range between $2.79-2.81 \AA$, which agrees with the presence of a single $\mathrm{W}-\mathrm{W}$ bond and a +4 oxidation state for the tungsten atoms. The intermetallic bond length increases in the $P$ $\left[\mathrm{W}_{3} \mathrm{Se}_{4} \mathrm{Br}_{3}((R, R)-\mathrm{Me}-\mathrm{BPE})_{3}\right]^{+}$selenide cluster up to $2.87 \AA$, in agreement with the larger covalent radius of selenium atom. The same tendency is observed in the $\mathrm{W}-\left(\mu_{3}-\mathrm{Q}\right)$ and $\mathrm{W}-(\mu-\mathrm{Q})$ bond distances, which elongate $c a .0 .13 \AA$ when sulfur is replaced by selenium. Differences in the nonequivalent $\mathrm{W}-(\mu-\mathrm{Q})$ bond lengths are attributed to the trans effect of the bromine versus the 
phosphorus atoms of the diphosphine ligand. Finally, replacement of the diphosphine, Me-BPE by DUPHOS, has not significant effect on the complex bond lengths.

At present, the reasons behind the stereochemistry of this synthetic route are not clear although factors such interionic interactions and steric hindrance may have their influence. However, it seems clear that once the chirality of one metal center is defined, that of the other two is equally fixed.

\section{Conclusions}

Enantioselective synthesis of chiral group six $\left.\left[\mathrm{M}_{3} \mathrm{Q}_{4} \mathrm{X}_{3} \text { (diphosphine }\right)_{3}\right]^{+}$cluster complexes by excision of one dimensional $\left\{\mathrm{M}_{3} \mathrm{Q}_{7} \mathrm{X}_{4}\right\}_{\mathrm{n}}$ polymers using chiral phosphines has been extended to other cluster cores, namely $\mathrm{W}_{3} \mathrm{Se}_{4}$ and other diphosphines such as $(R, R)$-DUPHOS. This work confirms that chirality transfer from optically pure organic ligands to polymeric inorganic phases is a good and simple alternative to prepare enantiomerically pure $\mathrm{C}_{3}$ symmetry cluster complexes with backbone chirality in good yields. In all cases investigated, excision reactions using $(R, R)$-Me-BPE and $(R, R)$-DUPHOS diphosphines afford the $P-\mathrm{M}_{3} \mathrm{Q}_{4}$ stereoisomer while its $M-\mathrm{M}_{3} \mathrm{Q}_{4}$ enantiomer is invariably obtained when using $(S, S)$-diphosphines. The cuboidal geometry of the cluster core with a missing metal atom makes these complexes excellent candidates as potential metalloligands able to coordinate a second transition metal and afford enantiopure cubane-type $\mathrm{M}_{3} \mathrm{M}^{\prime} \mathrm{Q}_{4}$ complexes.

\section{Supplementary material}

CCDC-1008234 ([M-1]Br), CCDC-1008232 ([P-2]PF6) and CCDC-1008233 ([P-3]Br) contain the supplementary crystallographic data for this paper. These data can be obtained free of charge from de Cambridge Crystallographic Data Centre via www.ccdc.cam.ac.uk/data_requested/cif 


\section{Acknowledgements}

The financial support of the Spanish Ministerio de Economia y Competitividad (grants CTQ201123157), Universitat Jaume I (research project P1.1B2013-19) and Generalitat Valenciana (Prometeo/2009/053 and ACOMP/2013/215) is gratefully acknowledged. The authors also thank the Serveis Central d'Instrumentació Cientifica (SCIC) of the Universitat Jaume I for providing us with the mass spectrometry, NMR, circular dichroism and X-ray facilities.

\section{References}

[1] Yang, K. Y.; Haynes, C. A.; Spatzal, T.; Rees, D. C.; Howard, J. B., Biochemistry, (2014) 53, 333.

[2] Herbst, K.; Brorson, M.; Carlsson, A., Journal of Molecular Catalysis a-Chemical, (2010) $325,1$.

[3] Kogan, V. M.; Nikulshin, P. A.; Rozhdestvenskaya, N. N., Fuel, (2012) 100, 2.

[4] Bahn, C. S.; Tan, A.; Harris, S., Inorg. Chem., (1998) 37, 2770.

[5] Takei, I.; Wakebe, Y.; Suzuki, K.; Enta, Y.; Suzuki, T.; Mizobe, Y.; Hidai, M., Organometallics, (2003) 22, 4639.

[6] Takei, L.; Dohki, K.; Kobayashi, K.; Suzuki, T.; Hidai, M., Inorg. Chem., (2005) 44, 3768.

[7] Feliz, M.; Guillamon, E.; Llusar, R.; Vicent, C.; Stiriba, S. E.; Perez-Prieto, J.; Barberis, M., Chem.-Eur. J., (2006) 12, 1486.

[8] Guillamon, E.; Llusar, R.; Perez-Prieto, J.; Stiriba, S. E., J. Organomet. Chem., (2008) 693, 1723.

[9] Beltran, T. F.; Feliz, M.; Llusar, R.; Mata, J. A.; Safont, V. S., Organometallics, (2011) 30, 290.

[10] Sorribes, I.; Wienhofer, G.; Vicent, C.; Junge, K.; Llusar, R.; Beller, M., Angewandte Chemie-International Edition, (2012) 51, 7794.

[11] Larionov, S. V.; Myachina, L. I.; Romanenko, G. V.; Tkachev, A. V.; Sheludyakova, L. A.; Ikorskii, V. N.; Boguslavskii, E. G., Russian Journal of Coordination Chemistry, (2001) 27, 423. 
[12] Shabalina, I. Y.; Kirin, V. P.; Maksakov, V. A.; Virovets, A. V.; Golovin, A. V.; Agafontsev,

A. M.; Tkachev, A. V., Russian Journal of Coordination Chemistry, (2008) 34, 286.

[13] Salomon, C.; Dal Molin, S.; Fortin, D.; Mugnier, Y.; Boere, R. T.; Juge, S.; Harvey, P. D., Dalton Transactions, (2010) 39, 10068.

[14] Estevan, F.; Feliz, M.; Llusar, R.; Mata, J. A.; Uriel, S., Polyhedron, (2001) $20,527$.

[15] Feliz, M.; Llusar, R.; Uriel, S.; Vicent, C.; Humphrey, M. G.; Lucas, N. T.; Samoc, M.; Luther-Davies, B., Inorg. Chim. Acta, (2003) 349, 69.

[16] Algarra, A. S. G.; Basallote, M. G.; Fernandez-Trujillo, M. J.; Llusar, R.; Safont, V. S.; Vicent, C., Inorg. Chem., (2006) 45, 5774.

[17] Algarra, A. G.; Basallote, M. G.; Fernandez-Trujillo, M. J.; Guillamon, E.; Llusar, R.; Segarra, M. D.; Vicent, C., Inorg. Chem., (2007) 46, 7668.

[18] Algarra, A. G.; Basallote, M. G.; Fernandez-Trujillo, M. J.; Feliz, M.; Guillamon, E.; Llusar, R.; Sorribes, I.; Vicent, C., Inorg. Chem., (2010) 49, 5935.

[19] Basallote, M. G.; Fernandez-Trujillo, M. J.; Pino-Charnorro, J. A.; Beltran, T. F.; Corao, C.; Llusar, R.; Sokolov, M.; Vicent, C., Inorg. Chem., (2012) 51, 6794.

[20] Beltran, T. F.; Feliz, M.; Llusar, R.; Safont, V. S.; Vicent, C., Eur. J. Inorg. Chem., (2013) 2013, 5797.

[21] Avarvari, N.; Kirakci, K.; Llusar, R.; Polo, V.; Sorribes, I.; Vicent, C., Inorg. Chem., (2010) 49, 1894.

[22] Katsuki, T.; Sharpless, K. B., J. Am. Chem. Soc., (1980) 102, 5974.

[23] Knowles, W. S.; Sabacky, M. J., Chem. Commun., (1968), 1445.

[24] Ohta, T.; Takaya, H.; Noyori, R., Inorg. Chem., (1988) 27, 566.

[25] Campian, M. V.; Perutz, R. N.; Procacci, B.; Thatcher, R. J.; Torres, O.; Whitwood, A. C., J. Am. Chem. Soc., (2012) 134, 3480.

[26] Meggers, E., Eur. J. Inorg. Chem., (2011), 2911.

[27] Crassous, J., Chem. Soc. Rev., (2009) 38, 830.

[28] Constable, E. C., Chem. Soc. Rev., (2013) 42, 1637. 
[29] Frantz, R.; Guillamon, E.; Lacour, J.; Llusar, R.; Polo, V.; Vicent, C., Inorg. Chem., (2007) 46, 10717.

[30] Llusar, R.; Uriel, S., Eur. J. Inorg. Chem., (2003), 1271.

[31] Cotton, F. A.; Kibala, P. A.; Matusz, M.; McCaleb, C. S.; Sandor, R. B. W., Inorg. Chem., (1989) 28, 2623.

[32] Fedin, V. P.; Sokolov, M. N.; Myakishev, K. G.; Gerasko, O. A.; Fedorov, V. Y.; Macicek, J., Polyhedron, (1991) 10, 1311.

[33] MASSLYNX, e. W. L. M., MA, 2005,

[34] Agilent, CrysAlisPro version 171.36.24; Agilent Technologies, Santa Clara, CA, 2012

[35] Busing, W. R.; Levy, H. A., Acta Crystallographica, (1957) 10, 180.

[36] Clark, R. C.; Reid, J. S., Acta Crystallographica Section A, (1995) 51, 887.

[37] Bruker Analitytical X-Ray Systems:Madison, W., SAINT, In (2001).

[38] Scheldrick, G. M., SADABS, Göttingen, (1996).

[39] Palatinus, L.; Chapuis, G., J. Appl. Crystallogr., (2007) 40, 786.

[40] Sheldrick, G. M., Acta Crystallographica Section A, (2008) 64, 112.

[41] Dolomanov, O. V.; Bourhis, L. J.; Gildea, R. J.; Howard, J. A. K.; Puschmann, H., J. Appl. Crystallogr., (2009) 42, 339.

[42] Brandenburg, K.; Putz, H., Crystal Impact, GbR, Bonn, Germany, (2006),

[43] Flack, H. D., Acta Crystallographica Section A, (1983) 39, 876.

[44] Bernardinelli, G.; Flack, H. D., Acta Crystallographica Section A, (1985) 41, 500.

[45] Flack, H. D.; Bernardinelli, G., Acta Crystallographica Section A, (1999) 55, 908. 